\title{
Enabling conditions for an equitable and sustainable blue economy
}

https://doi.org/10.1038/s41586-021-03327-3

Received: 29 June 2020

Accepted: 4 February 2021

Published online: 17 March 2021

Check for updates

\section{Andrés M. Cisneros-Montemayor ${ }^{1 凶}$, Marcia Moreno-Báez ${ }^{2}$, Gabriel Reygondeau $^{3}$, William W. L. Cheung ${ }^{3}$, Katherine M. Crosman ${ }^{4}$, Pedro C. González-Espinosa ${ }^{5}$, Vicky W. Y. Lam ${ }^{3}$, Muhammed A. Oyinlola ${ }^{3}$, Gerald G. Singh ${ }^{6}$, Wilf Swartz ${ }^{7}$, Chong-wei Zheng $^{8}$ \& Yoshitaka Ota ${ }^{4}$}

The future of the global ocean economy is currently envisioned as advancing towards a 'blue economy'-socially equitable, environmentally sustainable and economically viable ocean industries ${ }^{1,2}$. However, tensions exist within sustainable development approaches, arising from differing perspectives framed around natural capital or social equity. Here we show that there are stark differences in outlook on the capacity for establishing a blue economy, and on its potential outcomes, when social conditions and governance capacity-not just resource availability-are considered, and we highlight limits to establishing multiple overlapping industries. This is reflected by an analysis using a fuzzy logic model to integrate indicators from multiple disciplines and to evaluate their current capacity to contribute to establishing equitable, sustainable and viable ocean sectors consistent with a blue economy approach. We find that the key differences in the capacity of regions to achieve a blue economy are not due to available natural resources, but include factors such as national stability, corruption and infrastructure, which can be improved through targeted investments and cross-scale cooperation. Knowledge gaps can be addressed by integrating historical natural and social science information on the drivers and outcomes of resource use and management, thus identifying equitable pathways to establishing or transforming ocean sectors ${ }^{1,3,4}$. Our results suggest that policymakers must engage researchers and stakeholders to promote evidence-based, collaborative planning that ensures that sectors are chosen carefully, that local benefits are prioritized, and that the blue economy delivers on its social, environmental and economic goals.
As originally conceived by the Small Island Developing States of the United Nations (UN), a blue economy intends to be economically viable (prosperous) and environmentally sustainable, but also culturally appropriate and focused on social equity and well-being ${ }^{1,2}$. This is reflected in the UN Sustainable Development Goal ${ }^{5} 14.7$, and in research and policy publications that reference related terms such as 'blue growth' and a 'sustainable ocean economy'2,6,7. However, recent plans from governments, trade associations, civil society and intergovernmental organizations tend to focus primarily on the resources necessary for industrial expansion and economic growth of multiple ocean sectors instead of equitable outcomes from these sectors ${ }^{1,8}$. These discourses are similar to business-as-usual development, which is worrying given the effects of overexploitation on ocean health ${ }^{9}$ and coastal economies ${ }^{10}$. These effects are compounded by gradual stresses and extreme events from climate change ${ }^{10,11}$, which disproportionately affect vulnerable human populations ${ }^{12-14}$. As a result, some groups have received growing interest in a blue economy with skepticism and expressed concern that it will become a tool by which traditional users are excluded from ocean development ${ }^{15}$. Following from such sustainability and environmental justice concerns, and building from current blue economy discourses and research, our analysis identifies the areas of investment and research necessary to develop available ocean resources in a manner consistent with a blue economy that is socially equitable, environmentally sustainable and economically viable ${ }^{3}$.

Building on available global data (see Supplementary Information 1 for full indicator list and descriptions), we quantify and map the current capacity of geographic or jurisdictional areas to establish an equitable, sustainable, and viable blue economy ('blue economy capacity'), and analyse the results at global, regional and national scales, considering both biophysical resources for sector development ('resource availability'), and enabling conditions for subsequent advancement of well-being ('enabling conditions') ${ }^{3,6}$. Enabling conditions comprise criteria related to social equity (human rights, gender equality, group and economic equity, and corruption) ${ }^{16,17}$, environmental sustainability

${ }^{1}$ Institute for the Oceans and Fisheries, University of British Columbia, Vancouver, British Columbia, Canada. ${ }^{2}$ School of Marine and Environmental Programs, University of New England,

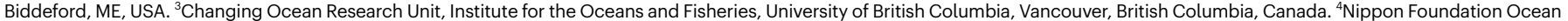
Nexus Center, EarthLab, University of Washington, Seattle, WA, USA. ${ }^{5}$ Department of Geography, University of British Columbia, Vancouver, British Columbia, Canada. ${ }^{6}$ Department of

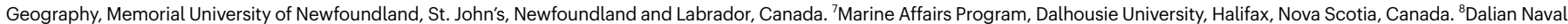
Academy, Dalian, China. ${ }^{凶}$-mail: a.cisneros@oceans.ubc.ca 


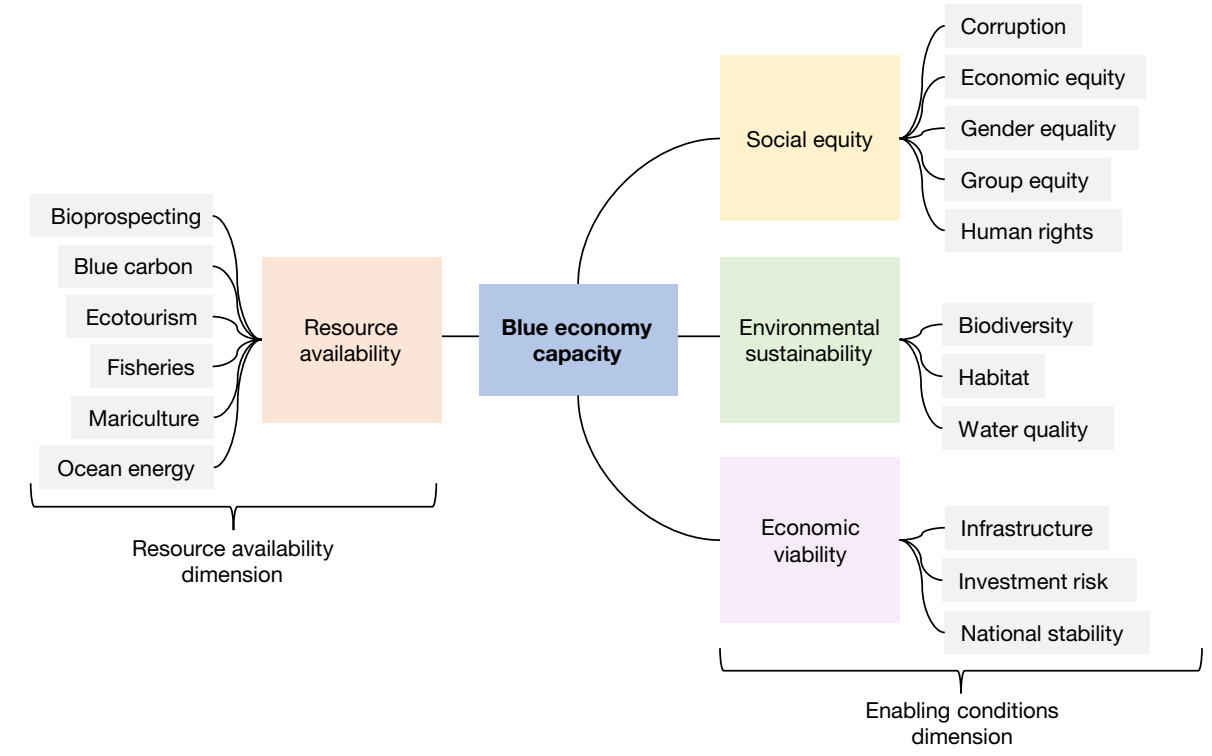

Fig. 1 Dimensions $(n=2)$ and criteria $(n=17$, grey boxes) used to evaluate the capacity to establish an equitable, sustainable and viable blue economy ('blue economy capacity'). The resource availability dimension here pertains to six specific ocean economy sectors. The enabling conditions dimension comprises three facets of development: social equity,

environmental sustainability and economic viability, each with corresponding criteria. Indicators informing each criterion $(n=33)$ are presented in Supplementary Information 1 , including all sources and descriptions. Indicators are evaluated for $0.5^{\circ} \times 0.5^{\circ}$ cells throughout the oceans based on sector observations and reviews using the fuzzy logic model explained in the Methods.

The main contributors to differences in blue economy capacity (based on similarity of percentages (SIMPER) and analysis of similarities (ANOSIM) analyses, see Methods; $R=0.24, P<0.001$ ) across spatial cells were human rights (12\%), national stability (11\%), corruption (11\%), and mariculture potential (10\%) (see Extended Data Table 1). Across regions, enabling conditions criteria that consistently ranked lowest were infrastructure, economic equity, group equity and human rights (Fig. 3). Sectors with higher resource availability scores were bioprospecting, ecotourism, ocean energy and mariculture; others, such as fisheries and blue carbon, were sometimes high but limited to specific places, appearing as regional outliers (Fig. 3).

Analysing scores within or between territories is beyond the scope of this study, but we found no correlation (linear regression; $R^{2}=0.001$, $P=0.11$ ) between territory scores for resource availability and enabling conditions. In Fig. 4a we label some examples to highlight that areas with comparable resources can have very different enabling conditions for their development and thus different blue economy capacity (Fig. 4b), underlining the need to expand planning beyond resource availability.

\section{Discussion}

Human well-being is a key goal of global development ${ }^{5}$, and high-level policies for oceans emphasize a need for equitable economies within and between nations ${ }^{2}$. This study does not address gaps between these narratives and real-world actions, but examines the extent to which equitable and sustainable benefits are likely to be achievable in ocean economies worldwide, based on current available resources and enabling governance conditions. First, natural resources are widely but patchily distributed across the oceans (Fig. 2b), so not many areas will be able to competitively develop multiple sectors simultaneously (Fig. 3). Prior research has shown that development based on living marine resources-including blue carbon, ecotourism, fishing and mariculture-can be important at local scales but may not be ecologically sustainable or socially desirable at larger scales ${ }^{3,4}$. In these cases, stakeholders may feel misled by growth projections revealed to be unattainable.Second-and perhaps more importantly for a blue 
a

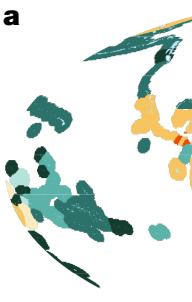

nabling conditions

$\leq 30 \leq 60 \leq 90$

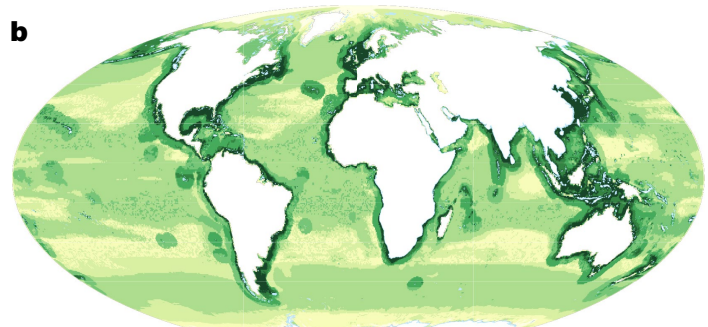

Resource availability

$\leq 10 \leq 55 \leq 100$

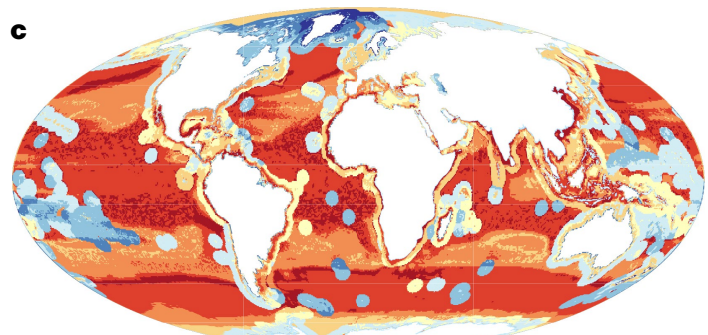

EC-RA gap

$\leq-32 \leq 10 \leq 65$

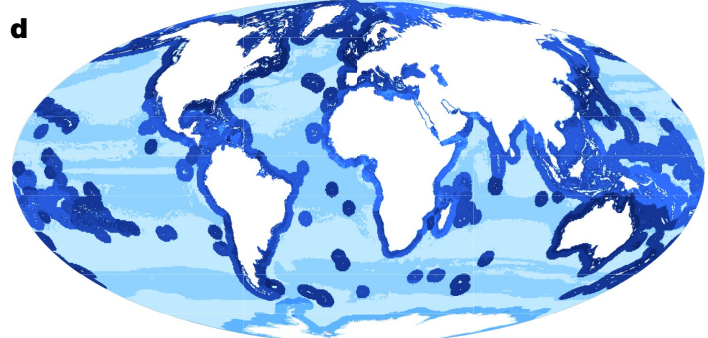

Blue economy capacity

$$
\leq 10 \leq 50 \leq 90
$$

Fig. 2 | Distribution of dimension scores $\left(0.5^{\circ} \times 0.5^{\circ}\right.$ cells, $\left.n=183,431\right)$ across oceans, regions and development groups. a, Enabling conditions for blue economy establishment (comprising social equity, economic viability and environmental sustainability). b, Resource availability for blue economy establishment (comprising bioprospecting, blue carbon, ecotourism, fisheries, mariculture, ocean energy).c, Difference between enabling conditions and resource availability scores ('EC-RA gap'). Red (blue) indicates an enabling condition score less (more) than the resource availability score. d, Current capacity for establishing an equitable, sustainable and viable blue economy ('blue economy capacity'), based on indicators for environmental

economy approach ${ }^{3}$-across regions and development categories there are widespread gaps in key enabling conditions (for example, economic and group equity, protection of human rights, environmental regulations, infrastructure) needed to ensure equitable, sustainable and Blue economy $\quad$ Enabling conditions Resource availability

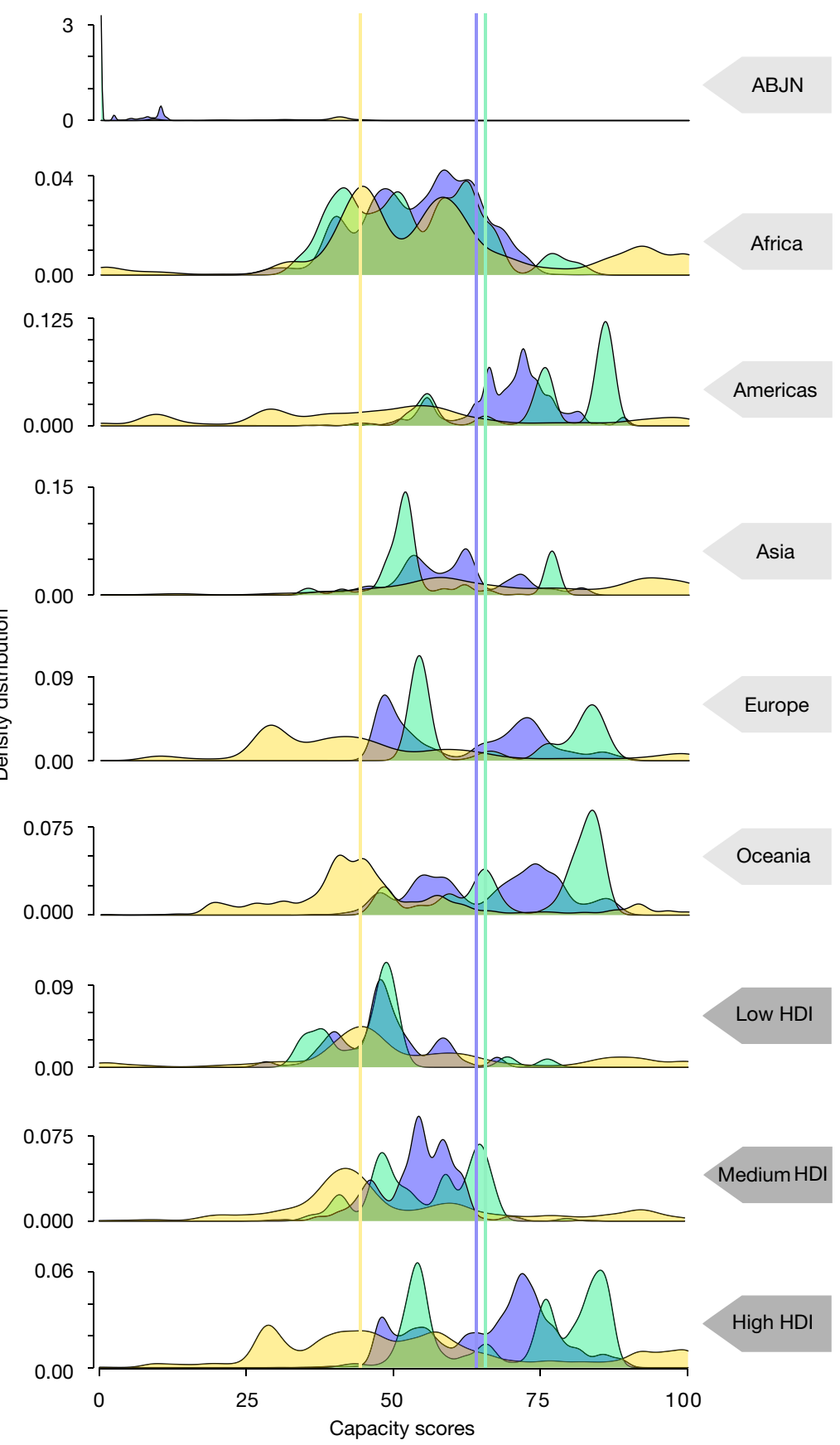

conditions and resource availability criteria evaluated through a fuzzy logic model (see Methods). e, Distribution of blue economy capacity, enabling conditions and resource availability cell scores, showing differences in enabling conditions and resource availability within and between regions (high seas areas beyond national jurisdiction, $\mathrm{ABNJ}, n=99,154$; Africa, $n=5,584$; Americas, $n=24,145$; Asia, $n=9,483$; Europe, $n=19,595$; Oceania, $n=15,143$ ) and development categories (low, $n=3,209$; medium, $n=6,757$; high, $n=60,198$ ). Vertical lines across panels show global median scores for resource availability (yellow), enabling conditions (green), and blue economy capacity (blue).

viable ocean development (Figs. 2c-e, 3). It is these socioeconomic and governance factors related to enabling conditions-and not available resources-that account for the most differences (Extended Data Fig. 1) in the current capacity of geographic or jurisdictional areas to 


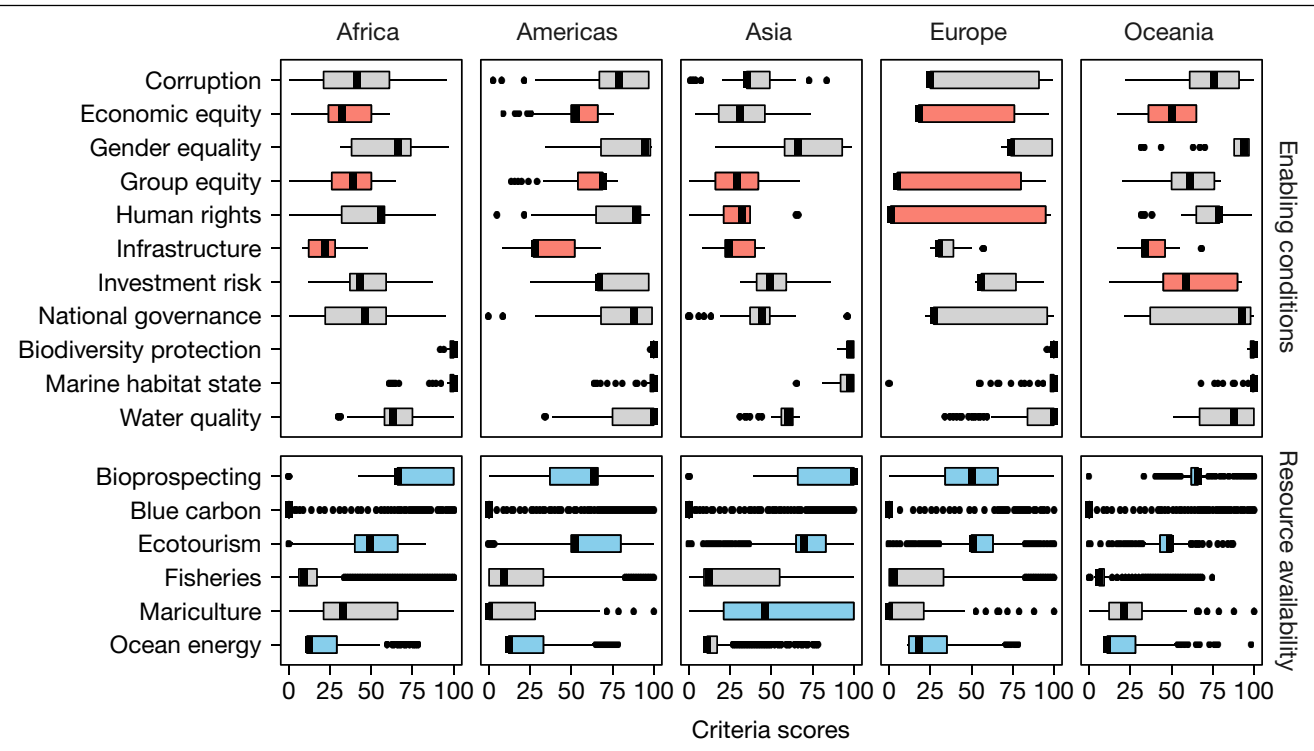

Fig. 3 Criteria scores by dimension and region. Data for each region include all $0.5^{\circ} \times 0.5^{\circ}$ cells in the EEZs of the corresponding jurisdictions (Africa, $n=5,584$; Americas, $n=24,145$; Asia, $n=9,483$; Europe, $n=19,595$; Oceania, $n=15,143)$. The three lowest median scores for enabling conditions criteria for each region are highlighted in red, and three highest scores for resource availability sectors in blue. Box limits indicate lower and upper quartiles; vertical lines are median values; whiskers indicate minimum and maximum values of $1.5 \times$ the interquartile range; points are outlier values. establish sectors consistent with a blue economy (Fig. 2e), but they are also ones that can be addressed by targeted investment.

Our results show clear trends in available resources and current enabling conditions that can inform transitions towards a blue economy, but we recognize uncertainties inherent in our data and model assumptions. For example, high-resolution environmental datasets such as those used here (Supplementary Information 1) may apply statistical approaches to interpolate observations, and are subsequently aggregated to our $0.5^{\circ} \times 0.5^{\circ}$ grid, allowing for robust analysis of global patterns but potentially obscuring local conditions. Even where local-scale analyses are generally consistent with global indicators, they also add essential context for effective planning and implementation ${ }^{22}$. Similarly, indicators related to enabling conditions are generally collated at national scales and may mask differences in de facto conditions within reporting jurisdiction ${ }^{23,24}$, which must be addressed at finer scales. Such indicators may also reflect development assumptions that do not specifically focus on equitable distribution of costs and benefits, and instead prioritize markets and resource conservation grounded in natural capital approaches ${ }^{24,25}$. Assumptions about the contribution of social or environmental factors to blue economy capacity may also change as new technologies enable new or more efficient industries, climate effects alter marine ecosystems, and shifting social objectives and preferences change desired sectors or pathways of development ${ }^{6,26}$. This is an important limitation of our results, and future applications must modify assumptions and data given specific goals and conditions, even when territories have common guidelines (for example, Sustainable Development Goals).

At the regional level, the Asia region had the widest gap between dimension scores, owing not only to lower enabling conditions but also to high resource availability (Fig. 3). This includes exceptionally high biodiversity and large mangrove ecosystems (for example, in the Coral Triangle, in southeastern Asia) (Fig. 2c), with high potential for the development of ecotourism, bioprospecting and mariculture (Fig. 4). Ocean-based development plans for China, Taiwan and Bangladesh do prioritize mariculture, but also sectors such as shipping, port construction and large-scale ocean energy projects ${ }^{27-29}$, which have potential but may encounter challenges related to inequitable benefits and uneven existing infrastructure (Fig. 3). Similar challenges have been anticipated in African blue economy plans ${ }^{30}$, which emphasize use of marine spatial planning tools to accommodate emerging sectors such as mariculture, ocean energy and shipping infrastructure, and solidify legal claims to mineral and oil resources ${ }^{30,31}$. Living marine resources may indeed allow for the establishment of multiple sectors (Fig. 3), but a blue economy must carefully consider ecological and social outcomes in the context of African development goals focused on local livelihoods and food security ${ }^{30}$. For example, mariculture may increase food production and decrease pressure on wild stocks ${ }^{32}$, but expansion that is focused on high-value species intended for export may not increase local food availability and could even decrease it by using fish for farm feed ${ }^{33}$ and degrading productive habitats such as mangroves that sustain local fisheries ${ }^{34}$.

The Americas, Europe and Oceania regions generally scored higher on enabling conditions than on resource availability (Fig. 2e), but factors such as infrastructure, economic and group equity can be highly variable between and within jurisdictions (Fig. 3). In the Americas, natural capital approaches to ocean development are most common but specific plans are in relatively early stages compared with Europe and Oceania, with the exception of some Caribbean nations and a general interest in ecotourism and mariculture ${ }^{35,36}$. The European Union (EU) has focused on sectors such as offshore wind energy and mariculture and initially excluded fisheries ${ }^{37}$, reflecting the different objectives for ocean development across regions. Fisheries have been included in more recent EU plans ${ }^{38}$, given scientific evidence of their potential for growth if economic efficiency is improved ${ }^{37}$. By contrast, Oceania has prioritized community objectives, traditional resource uses, and emerging sectors that can be developed in accordance with local customs ${ }^{39}$. Across regions, participatory design of contextually appropriate goals and strategies could help align economic incentives and identify local investment needs. Recognizing and including a wide range of stakeholders and perspectives is a foundational step in this process of transformation ${ }^{1,2,6}$.

All coastal nations could develop and transform their ocean economies to advance equity and sustainability (Fig. 4a), and our results show that most marine renewable resources are indeed within EEZs with clearer rights and responsibilities (Fig. 2b, e). It is important, however, to avoid conflicts and find synergies between existing and emerging sectors-and development goals ${ }^{40}$ - whenever possible. For example, well planned blue carbon sites could simultaneously 

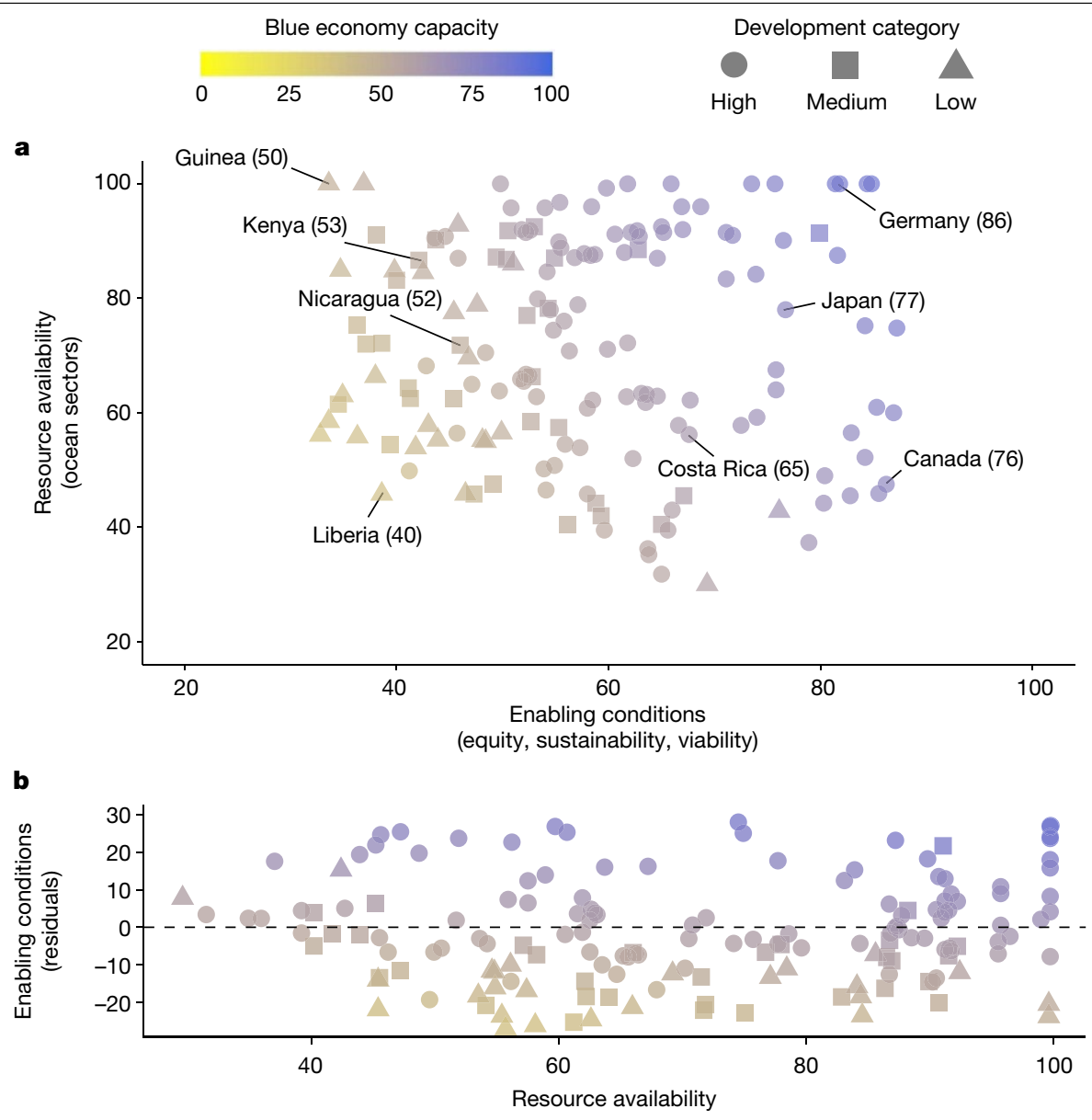

Fig. 4 | Resource availability and enabling conditions scores for coastal territories. a, Symbol shapes indicate UN HDI development category: circle, high and very high; square, medium; triangle, low. Symbol colours indicate a higher or lower capacity to establish blue economy sectors that are equitable, sustainable and viable ('blue economy capacity'); some territories are labelled as examples. We note that scores do not reflect the current relative importance

contribute to carbon sequestration, habitat protection, artisanal fisheries and ecotourism ${ }^{3,41}$. Ecotourism, if carefully implemented, can be important for rural communities but also incentivizes conservation and infrastructure investments with wider benefits ${ }^{42}$. Ocean energy investment has lagged in the developing world due to infrastructure and economic viability conditions $\mathrm{s}^{21,43}$ (Fig. 3), but focusing on marginalized communities could shift investment towards areas that are difficult or expensive to connect to existing grids ('last-mile electrification'). Global marine biodiversity is double that found in terrestrial systems ${ }^{44}$ and bioprospecting could add economic incentives for conservation ${ }^{45}$. However, disparities in local capacity can lead to unequal sharing of benefits from such resources-for example, a single corporation has registered $47 \%$ of marine genetic sequences included in patents worldwide $^{46}$-again highlighting the need for a focus on social equity within a blue economy that supports wider well-being ${ }^{3}$. In addition, as we face unprecedented effects from the ongoing COVID-19 pandemic, all sectors need to consider risks of unexpected external shocks.

Planning and development of ocean-based sectors can be particularly difficult owing to the nature of ocean spaces, including highly connected and shifting resources and effects, often less-well-defined jurisdictional capacity and responsibilities ${ }^{47}$, and the prevalence of vulnerable resource-dependent communities along many of the world's coasts ${ }^{6,13,16}$. However, this study shows that data and methods do exist to inform strategies that recognize such challenges and to prioritize pertinent social and ecological contexts and goals in policy. This includes of oceans to particular territories and only consider the six sectors included in this study. b, Residual fits between enabling conditions and resource availability dimensions scores showing the effect on blue economy capacity scores. Dashed line is at 0 , showing the distribution of positive and negative residual values.

organizations seeking to maximize effects of development interventions and regional initiatives; governments considering synergies and factors likely to hinder or enable the establishment of a blue economy; and actors at any scale seeking to distinguish constraints and risks that are tractable to their own policy change from those that require longer-term or higher-scale actions ${ }^{48}$. In all cases, this study highlights that recognizing that the key factors to be addressed are related to enabling conditions-and not only natural resource availability-is a foundational step towards a strategic approach to achieving a blue economy.

\section{Online content}

Any methods, additional references, Nature Research reporting summaries, source data, extended data, supplementary information, acknowledgements, peer review information; details of author contributions and competing interests; and statements of data and code availability are available at https://doi.org/10.1038/s41586-021-03327-3.

1. Bennett, N. J. et al. Towards a sustainable and equitable blue economy. Nat. Sustain. 2 991-993 (2019).

2. Österblom, H., Wabnitz, C. C. C. \& Tladi, D. Towards Ocean Equity Blue Paper https://www. oceanpanel.org/blue-papers/towards-ocean-equity (World Resources Institute, 2020).

3. Cisneros-Montemayor, A. M. et al. Social equity and benefits as the nexus of a transformative Blue Economy: a sectoral review of implications. Mar. Policy 109, 103702 (2019). 
4. Caswell, B. A. et al. Something old, something new: historical perspectives provide lessons for blue growth agendas. Fish Fish. 21, 774-796 (2020).

5. United Nations. Transforming Our World: The 2030 Agenda for Sustainable Development Report No. A/RES/70/1 https://sustainabledevelopment.un.org/post2015/ transformingourworld/publication (UN, 2015).

6. Allison, E. H. et al. The Human Relationship with Our Ocean Planet Blue Paper https:// oceanpanel.org/blue-papers/HumanRelationshipwithOurOceanPlanet (World Resources Institute, 2020).

7. European Commission. The EU Blue Economy Report 2020 https://ec.europa.eu/ maritimeaffairs/sites/maritimeaffairs/files/2020_06_blueeconomy-2020-ld_final.pdf (European Union, 2020).

8. Voyer, M., Quirk, G., Mcllgorm, A. \& Azmi, K. Shades of blue: what do competing interpretations of the Blue Economy mean for oceans governance? J. Environ. Policy Plann. 20, 595-616 (2018).

9. Laffoley, D. et al. Eight urgent, fundamental and simultaneous steps needed to restore ocean health, and the consequences for humanity and the planet of inaction or delay. Aquat. Conserv. 30, 194-208 (2020).

10. Sumaila, U. R. et al. Benefits of the Paris Agreement to ocean life, economies, and people. Sci. Adv. 5, eaau3855 (2019).

11. Frölicher, T. L., Fischer, E. M. \& Gruber, N. Marine heatwaves under global warming. Nature 560, 360-364 (2018)

12. Golden, C. et al. Fall in fish catch threatens human health. Nature 534, 317-320 (2016)

13. Cisneros-Montemayor, A. M., Pauly, D., Weatherdon, L. V. \& Ota, Y. A global estimate of seafood consumption by coastal indigenous peoples. PLoS One 11, e0166681 (2016).

14. Blasiak, R. et al. Climate change and marine fisheries: least developed countries top global index of vulnerability. PLoS One 12, e0179632 (2017).

15. Bennett, N. J., Govan, H. \& Satterfield, T. Ocean grabbing. Mar. Policy 57, 61-68 (2015).

16. Teh, L. C. L. et al. The role of human rights in implementing socially responsible seafood. PLoS One 14, e0210241 (2019).

17. Finkbeiner, E. M. et al. Reconstructing overfishing: moving beyond Malthus for effective and equitable solutions. Fish Fish. (2017).

18. Halpern, B. S. et al. An index to assess the health and benefits of the global ocean. Nature 488, 615-620 (2012).

19. Shen, L., Wu, Y. \& Zhang, X. Key assessment indicators for the sustainability of infrastructure projects. J. Constr. Eng. Manage. 137, 441-451 (2011).

20. Sekkat, K. \& Veganzones-Varoudakis, M.-A. Openness, investment climate, and FDI in developing countries. Rev. Dev. Econ. 11, 607-620 (2007).

21. Cisneros-Montemayor, A. M. A Blue Economy: equitable, sustainable, and viable development in the world's oceans. In Predicting Future Oceans: Sustainability of Ocean and Human Systems Amidst Global Environmental Change (eds Cheung, W. W. L. et al.) 395-404 (Elsevier, 2019).

22. Elfes, C. T. et al. A regional-scale ocean health index for Brazil. PLoS One 9, e92589 (2014).

23. da Cruz, N. F. \& Marques, R. C. Structuring composite local governance indicators. Policy Stud. 38, 109-129 (2016).

24. Merry, S. E. Measuring the world: indicators, human rights, and global governance. Curr. Anthropol. 52, S83-S95 (2011).

25. Toman, M. Why not to calculate value of world ecosystem services and natural capital. Ecol. Econ. 25, 57-60 (1998).

26. Ertör, I. \& Hadjimichael, M. Blue degrowth and the politics of the sea: rethinking the blue economy. Sustain. Sci. 15, 1-10 (2020).

27. Chen, C.-L. \& Qiu, G.-H. The long and bumpy journey: Taiwan's aquaculture development and management. Mar. Policy 48, 152-161 (2014).

28. Patil, P. G. et al. Toward a Blue Economy: A Pathway for Bangladesh's Sustainable Growth https://openknowledge.worldbank.org/handle/10986/30014 (World Bank, 2018).
29. Wenhai, L. et al. Successful Blue Economy examples with an emphasis on international perspectives. Front. Mar. Sci. https://doi.org/10.3389/fmars.2019.00261 (2019).

30. United Nations Economic Commission for Africa. Unlocking the Full Potential of the Blue Economy: Are African Small Island Developing States Ready to Embrace the Opportunities? https://repository.uneca.org/handle/10855/23170 (UN Economic Commission for Africa, 2014).

31. United Nations Economic Commission for Africa. Africa's Blue Economy: A Policy Handbook https://repository.uneca.org/handle/10855/23014 (UN Economic Commission for Africa, 2016).

32. Costello, C. et al. The future of food from the sea. Nature $\mathbf{5 8 8}, 95-100$ (2020).

33. Edwards, P., Zhang, W., Belton, B. \& Little, D. C. Misunderstandings, myths and mantras in aquaculture: its contribution to world food supplies has been systematically over reported. Mar. Policy 106, 103547 (2019).

34. Aburto-Oropeza, O. et al. Mangroves in the Gulf of California increase fishery yields. Proc. Natl Acad. Sci. USA 105, 10456-10459 (2008).

35. Patil, P. G., Virdin, J., Diez, S. M., Roberts, A. \& Singh, A. Toward A Blue Economy: A Promise for Sustainable Growth in the Caribbean; An Overview https://openknowledge.worldbank. org/handle/10986/25061 (World Bank, 2016).

36. Government of Grenada. Grenada: Blue Growth Coastal Master Plan Report No. AUS20778 https://clmeplus.org/app/uploads/2019/12/ Grenada-Blue-Growth-Coastal-Master-Plan-World-Bank.pdf (World Bank, 2016).

37. Boonstra, W. J., Valman, M. \& Björkvik, E. A sea of many colours - how relevant is Blue Growth for capture fisheries in the Global North, and vice versa? Mar. Policy 87, 340-349 (2018).

38. Council of the European Union. Declaration of the European Ministers Responsible for the Integrated Maritime Policy on Blue Growth (Valetta Declaration) https://data.consilium. europa.eu/doc/document/ST-8037-2017-INIT/en/pdf (EU, 2017).

39. Keen, M. R., Schwarz, A.-M. \& Wini-Simeon, L. Towards defining the Blue Economy: practical lessons from Pacific Ocean governance. Mar. Policy 88, 333-341 (2017).

40. Singh, G. G. et al. A rapid assessment of co-benefits and trade-offs among Sustainable Development Goals. Mar. Policy 93, 223-231 (2018).

41. Hejnowicz, A. P., Kennedy, H., Rudd, M. A. \& Huxham, M. R. Harnessing the climate mitigation, conservation and poverty alleviation potential of seagrasses: prospects for developing blue carbon initiatives and payment for ecosystem service programmes. Front. Mar. Sci. https://doi.org/10.3389/fmars.2015.00032 (2015).

42. Boley, B. B. \& Green, G. T. Ecotourism and natural resource conservation: the 'potential' for a sustainable symbiotic relationship. J. Ecotour. 15, 36-50 (2016).

43. Zheng, C. W. \& Pan, J. Assessment of the global ocean wind energy resource. Renew. Sustain. Energy Rev. 33, 382-391 (2014).

44. Gagné, T. O. et al. Towards a global understanding of the drivers of marine and terrestrial biodiversity. PLoS One 15, e0228065 (2020).

45. Hunt, B. \& Vincent, A. C. J. Scale and sustainability of marine bioprospecting for pharmaceuticals. Ambio 35, 57-64 (2006).

46. Blasiak, R., Jouffray, J.-B., Wabnitz, C. C., Sundström, E. \& Österblom, H. Corporate control and global governance of marine genetic resources. Sci. Adv. 4, eaar5237 (2018).

47. Guggisberg, S. The roles of nongovernmental actors in improving compliance with fisheries regulations. Rev. Eur. Comp. Intl Environ. Law 28, 314-327 (2019).

48. Nilsson, M., Griggs, H. \& Visbeck, M. Map the interactions between Sustainable Development Goals. Nature 534, 320-322 (2016).

Publisher's note Springer Nature remains neutral with regard to jurisdictional claims in published maps and institutional affiliations.

(c) The Author(s), under exclusive licence to Springer Nature Limited 2021 


\section{Methods}

This study uses a set of indicators from multiple disciplines integrated through a fuzzy logic model to evaluate the capacity of geographic or jurisdictional areas to establish ocean sectors consistent with a blue economy approach. This 'blue economy capacity' comprises two overarching dimensions: 'resource availability' considers criteria $(n=6)$ regarding the availability of natural resources that underpin ocean sectors; 'enabling conditions' considers criteria $(n=11)$ regarding the capacity to ensure that sectors are socially equitable, environmentally sustainable and economically viable (Fig. 1). Blue economy capacity, dimensions and criteria scores are informed by indicators $(n=33)$ based on a review of ocean sectors from the perspective of social, economic and ecological dimensions of sustainable development ${ }^{3}$. All indicator datasets were standardized into a global $0.5^{\circ} \times 0.5^{\circ}$ cell grid, which involved aggregating values when indicators had higher resolutions, or assuming corresponding cells had the same values when indicators were at larger (for example, national) scales (see Supplementary Information 1 and section 'Discussion'). Full descriptions of indicators, data sources and technical details are presented in Supplementary Information 1 .

Our analyses address several levels of aggregation, and scores for each of these geographic or jurisdictional areas represent median values over the grid cells they comprise. The smallest analytical units are individual $0.5 \times 0.5^{\circ}$ cells, followed by territories (most often nations, but also including overseas territories and disputed islands); subregions and regions (following UN categories); and development categories (high, medium, low), based on the UN HDI (which we do not use in our model). The UN HDI includes a 'very high' category, but for simplicity we combined these territories with the 'high' category.

We use a fuzzy logic model to evaluate indicators in terms of their contribution to heuristic categories ('sets') representing very limited, limited, high, and very high capacity for corresponding criteria, dimensions and blue economy (Fig. 1) scores ([0-100]). For example, high average wind speed, existing infrastructure and a well functioning economic system are all expected to contribute to higher capacity for developing offshore wind energy (ocean energy sector) within a blue economy (see Supplementary Information 2, Extended Data Fig. 1). Overlaps between the fuzzy sets are an explicit part of the fuzzy logic model and address potential uncertainties in the thresholds between categories, because an indicator value can be part of two or more categories at once ${ }^{49}$ (Extended Data Figs. 3-5).

Fuzzy set distributions were informed by observed relationships between current operations and underlying resources and site characteristics ${ }^{21}$ and prior reviews of ocean sector requirements ${ }^{3}$. See Supplementary Information 2 and Extended Data Fig. 1 for extended methods including a graphical example; Extended Data Figs. 2-4 show the fuzzy sets for every indicator in the model, their corresponding categories, and Supplementary Information 3 their underlying range and shape parameters. Observed data should be integrated into this approach whenever possible, but users can modify categories depending on objectives and contexts through expert elicitation ${ }^{50}$, especially in regional studies. This method is highly useful when policy goals are difficult to evaluate directly but can be informed by known relationships with underlying factors ${ }^{51}$, and has been used, for example, to gauge progress towards marine biodiversity targets ${ }^{50}$ or evaluate vulnerability of marine species to human activity ${ }^{52,53}$.

At the highest level of aggregation, we use an analysis of variance (ANOVA) test for differences in dimension and capacity scores between territories in different development categories (high, medium, low). Differences between cell criteria scores were tested using an analysis of similarities (ANOSIM) comparing among regions, using each territory within a region as a replicate. A similarity of percentages (SIMPER) analysis was then used to assess the effect of blue economy capacity criteria to differences between grid cells (for example, criteria 1 may account for $30 \%$ of differences, criteria $1+2$ for $40 \%$, etc.). SIMPER analyses are multivariate statistical procedures used in community ecology to calculate the relative contribution of species abundance to dissimilarity between ecosystems, according to the Bray-Curtis dissimilarity index. We used a linear regression to test for a possible relationship between territory-level scores for resource availability and enabling conditions (Fig. 4a), and plotted the fit residuals to highlight the relationship between these two scores and the blue economy capacity scores (Fig. 4b). We ensured that residuals were normally distributed, were homoscedastic, did not follow clear patterns, and that the models were not affected by influential outliers (QQ plots, standardized residual versus fitted value plots, scale location plots, residual versus leverage plots, Cook's distance measures of leverage and Levine's test of equal variance), with no issues found. All analyses were performed using the R 'base' and 'vegan' packages ${ }^{54,55}$.

\section{Data availability}

All data are available from the corresponding author upon reasonable request or at Data Dryad (https://doi.org/10.5061/dryad.63xsj3v1h). Indicator input data are also available from the sources and links presented in Supplementary Information 1.

\section{Code availability}

Custom code for this study is available from the corresponding author upon reasonable request.

49. Cox, E. The Fuzzy Systems Handbook: A Practitioners Guide to Building, Using, and Maintaining Fuzzy Systems (AP Professional, 1999).

50. Cisneros-Montemayor, A. M., Singh, G. G. \& Cheung, W. W. L. A fuzzy logic expert system for evaluating policy progress towards sustainability goals. Ambio 47, 595-607 (2017)

51. Andriantiatsaholiniaina, L. A., Kouikoglou, V. S. \& Phillis, Y. A. Evaluating strategies for sustainable development: fuzzy logic reasoning and sensitivity analysis. Ecol. Econ. 48, 149-172 (2004).

52. Jones, M. C. \& Cheung, W. W. L. Using fuzzy logic to determine the vulnerability of marine species to climate change. Glob. Change Biol. 24, e719-e731 (2017).

53. Cheung, W. W. L., Pitcher, T. J. \& Pauly, D. A fuzzy logic expert system to estimate intrinsic extinction vulnerabilities of marine fishes to fishing. Biol. Conserv. 124, 97-111 (2005).

54. Oksanen, J. et al. Package 'vegan' https://cran.ism.ac.jp/web/packages/vegan/vegan.pdf (2019).

55. R Core Team. R: A Language and Environment for Statistical Computing https:// www.r-project.org (R Foundation for Statistical Computing, 2020).

Acknowledgements This study is a product of the Nippon Foundation Ocean Nexus Center at EarthLab, University of Washington, in collaboration with the University of British Columbia. We thank reviewers J. Calado, B. Caswell, L. Crowder and A. Steven for their comments on the manuscript, and we thank E. H. Allison and U. R. Sumaila for comments on earlier versions of the work. G.G.S. acknowledges funding support from the Ocean Frontier Institute, through an award from the Canada First Research Excellence Fund. W.W.L.C. acknowledges funding support from the Natural Sciences and Engineering Research Council and the Social Sciences and Humanities Research Council of Canada, as well as advanced computing support from Compute Canada. A.M.C.-M. and Y.O. thank all members of the Nippon Foundation Nereus Program and Ocean Nexus for their comments on and support for this work.

Author contributions Conceptualization: A.M.C.-M. and Y.O. Methodology: A.M.C.-M., M.M.-B., Y.O., G.G.S., G.R. and W.W.L.C. Validation: A.M.C.-M., M.M.-B., G.G.S. and G.R. Formal analysis: A.M.C.-M., M.M.-B., G.R. and Y.O. Investigation: all authors. Resources: all authors. Data curation: A.M.C.-M., M.M.-B., G.R. and P.C.G.-E. Writing-original draft preparation: A.M.C.-M. and Y.O. Writing-review and editing: all authors. Visualization: A.M.C.-M., M.M.-B., P.C.G.-E. and G.R. Funding acquisition: Y.O., W.W.L.C. and A.M.C.-M.

Competing interests The authors declare no competing interests.

\section{Additional information}

Supplementary information The online version contains supplementary material available at https://doi.org/10.1038/s41586-021-03327-3.

Correspondence and requests for materials should be addressed to A.M.C.-M Peer review information Nature thanks João Calado, Bryony Caswell, Larry Crowder and Andrew Steven for their contribution to the peer review of this work. Peer reviewer reports are available.

Reprints and permissions information is available at http://www.nature.com/reprints. 
A

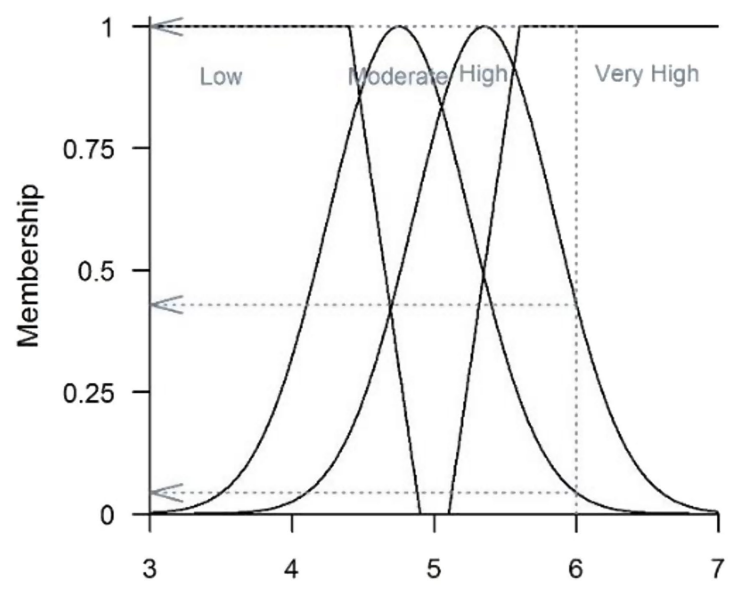

Criteria 1 (e.g. Wind Speed, $\mathrm{m} / \mathrm{s}$ )

\section{C}

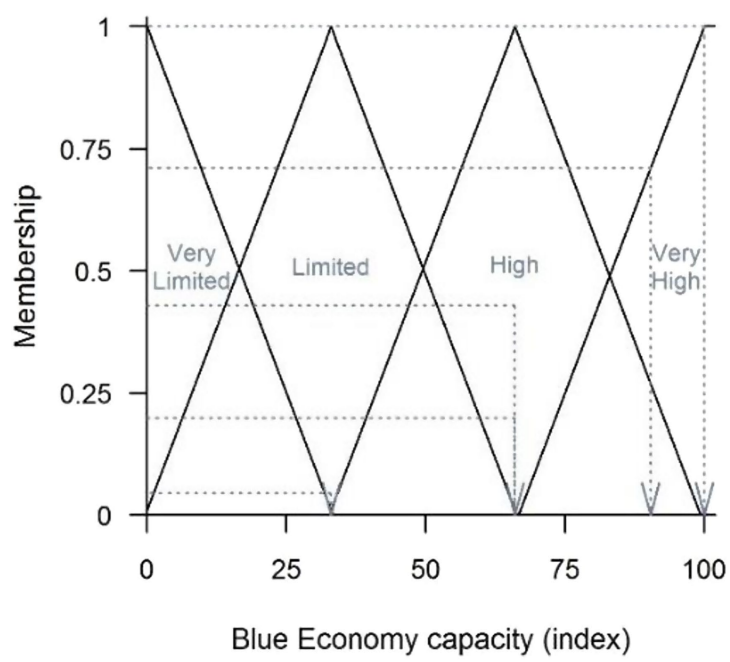

Extended Data Fig. 1 | Illustrative example of fuzzy logic model with two criteria. a, Criteria 1: average wind speed. b, Criteria 2: control of corruption. Both $\mathbf{a}$ and $\mathbf{b}$ each have four heuristic categories represented in fuzzy sets. c, Blue economy capacity. Degrees of membership are calculated for each
B

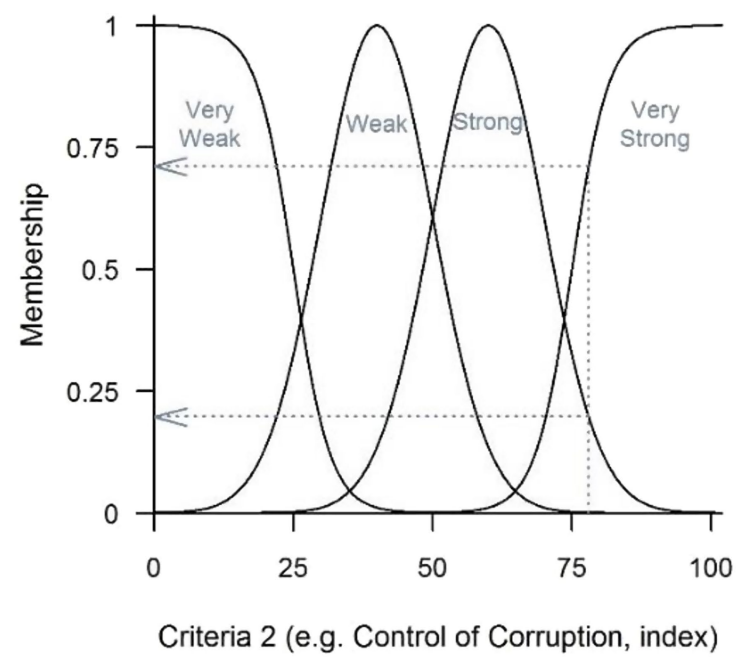

D

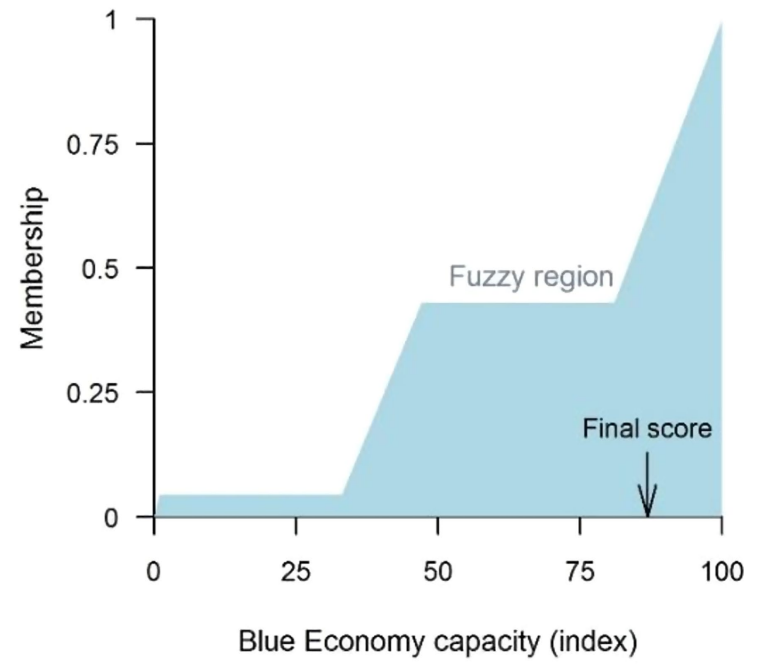

fuzzy set depending on their distribution, and correspond to fuzzy sets for the evaluation of blue economy capacity. d, To calculate a final score all capacity scores from corresponding indicator values are averaged, weighted by their fuzzy set memberships. 

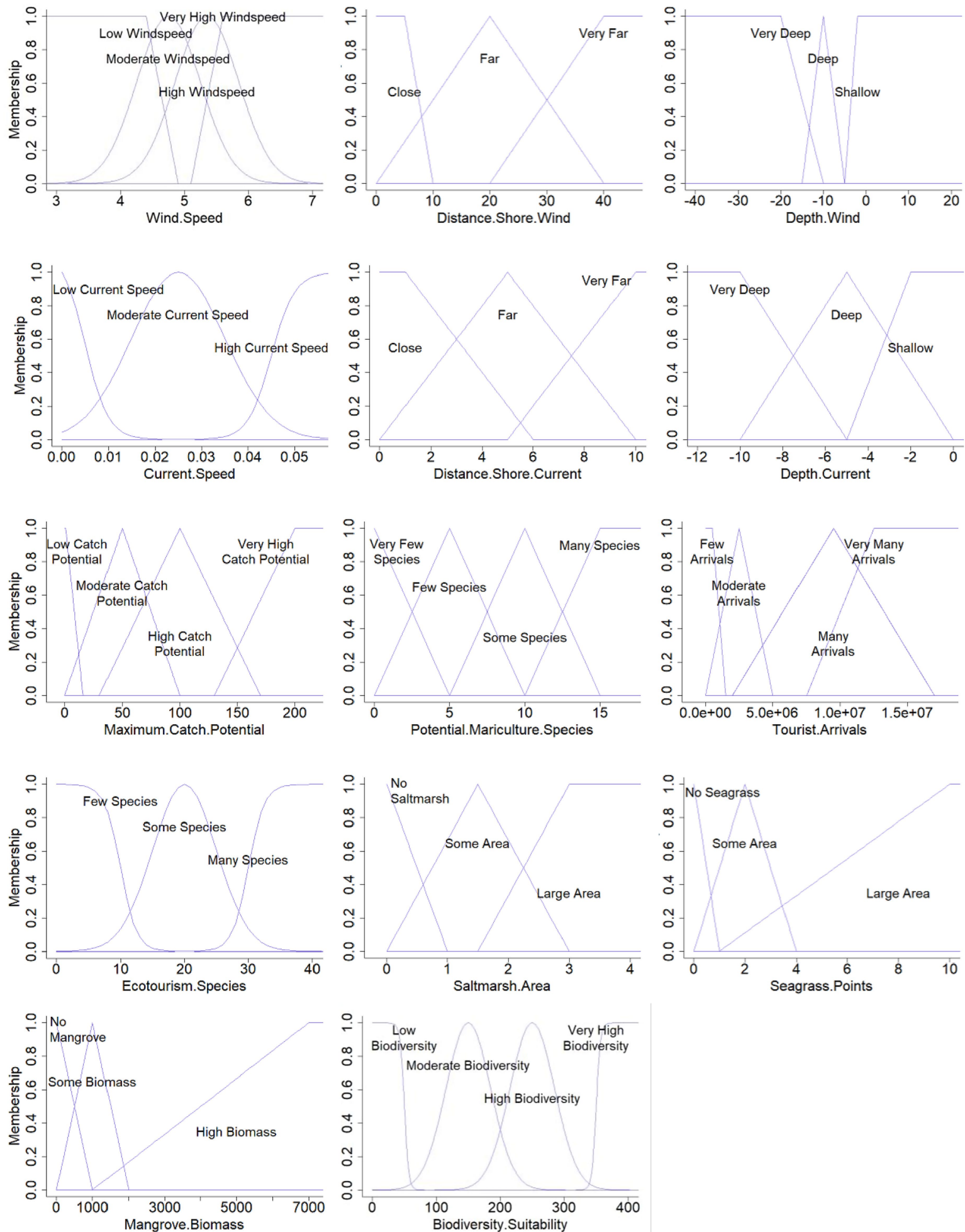

Extended Data Fig. 2 | Fuzzy sets for resource availability criteria. These are visual representations of the fuzzy sets for each indicator, including set shapes and thresholds, corresponding names and indicator ranges. 

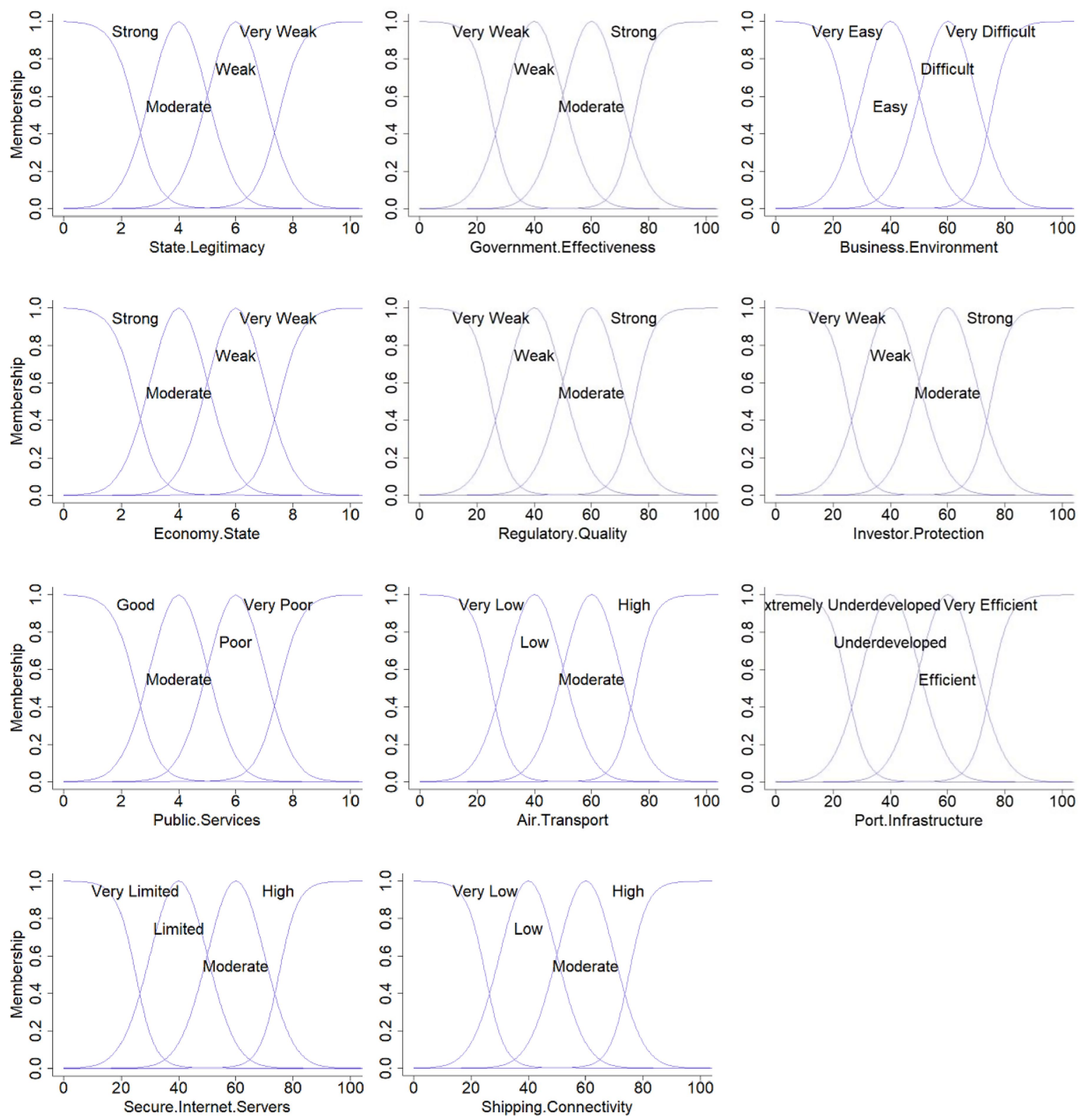

Extended Data Fig. 3 | Fuzzy sets for economic viability criteria. These are visual representations of the fuzzy sets for each indicator, including set shapes and thresholds, corresponding names and indicator ranges. 

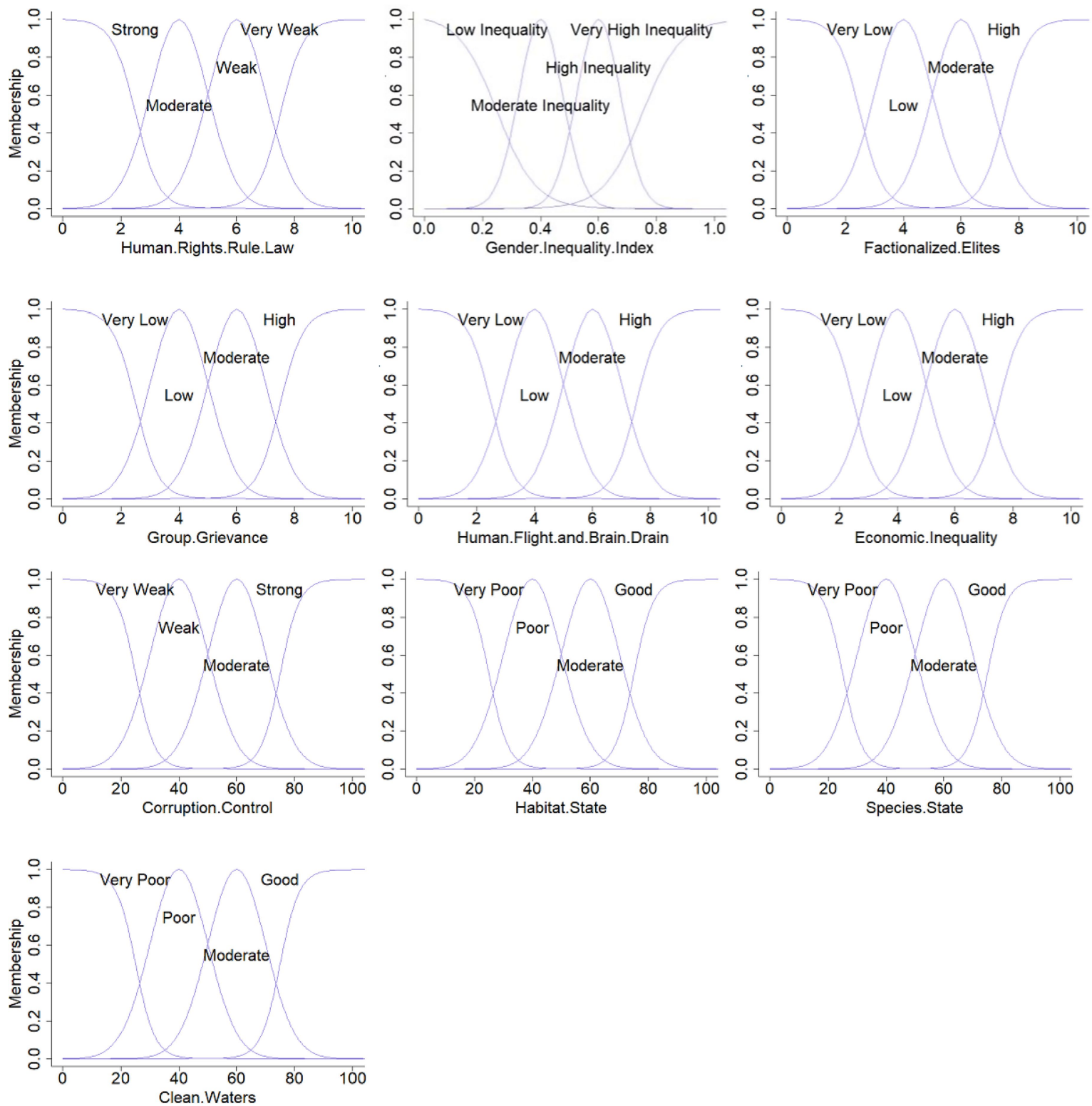

Extended Data Fig. 4 | Fuzzy sets for social equity and environmental sustainability criteria. These are visual representations of the fuzzy sets for each indicator, including set shapes and thresholds, corresponding names, and indicator ranges. 
Extended Data Table 1 | Criteria ranked by order of

contribution to differences between global regions

\begin{tabular}{ll}
\hline Criteria & Sum \\
\hline Human Rights & 0.120 \\
Corruption & 0.114 \\
National Stability & 0.113 \\
Mariculture & 0.105 \\
Water Quality & 0.099 \\
Group Equity & 0.092 \\
Investment Risk & 0.081 \\
Gender Equality & 0.077 \\
Bioprospecting & 0.068 \\
Economic Equity & 0.066 \\
Ecotourism & 0.054 \\
Infrastructure & 0.049 \\
Fisheries & 0.046 \\
Blue Carbon & 0.025 \\
Blue Energy & 0.017 \\
Marine Habitat State & 0.012 \\
Biodiversity Protection & 0.007 \\
\hline
\end{tabular}

Values show the contribution of each criteria to overall differences between regions, based on SIMPER and ANOSIM analyses. 